\title{
Formation and motion characteristics of summary fluid mud
}

\author{
Kunpeng $\mathrm{Li}^{1,2}$, Junhua Zhang ${ }^{1,2}$ and Huaibao $\mathrm{Ma}^{1,2}$ \\ ${ }^{1}$ Yellow River Institute of Hydraulic Research, Zhengzhou, China \\ ${ }^{2}$ Key Laboratory of Yellow River Sediment Research, Zhengzhou, China
}

Keywords: summary;fluid mud; motion characteristics;causes

\section{Introduction}

Fluid mud layer is close to the sediment hyperconcentrated water between it and the upper body of water has obvious interface, it has great mobility. Foreign fluid mud research began in the 1950s, Inglis and allen $(1957)^{[1]}$ at the time of the thames estuary sediment movement in great britain for the first time using a fluid mud; Then the fluid mud were found in the gironde estuary in france, the mississippi of the united states, Thailand weinan estuaries and other coastal estuary muddy; Migniot $(1968)^{[2]}$ and dutch engineering consulting association $(1968)^{[3]}$ were also used "cremede vase" and "sling mud" other names; Kirby and parker (1983) ${ }^{[4]}$ for a definition of the fluid mud;Parker and hooper (1994) ${ }^{[5]}$ has an alternative fluid mud with "high concentration of water in the sediment layer." Domestic fluid mud research began in the 1960s, which was first discovered in tianjin new harbor back silting study ${ }^{[6]}$, subsequently found in lianyun port,Shanghai port, and Yellow river estuary, Yangtze river estuary and other mucky ports estuaries;In recent years the three gorges reservoir, Xiaolangdi reservoir have also found that the presence of fluid mud.

Fluid mud is widely present in the estary,gulf,inland waterways,lakes and reservoirs; It is closely related to port and waterway silting, sailing depth use,reservoir sediment density current and water pollution problem; Thus causing a large number of researchers on the causes fluid mud,defining and motion characteristics, and aspects of research and exploration,We made a series of scientific research. But being limited field data and experimental conditions, At home and abroad in recent years it has been little progress in their research.

\section{Causes And Conditions Of Fluid Mud}

It has been made more consistent understanding of fluid mud: (1)Fine sediment in after starting, with the water to migrate into the fairway or off the cover region and silt, clay soil suspended sediment in the settlement process, due to flocculation, so that the formation of sediment flocculation of particles, to a certain concentration, flocculation pellets a honeycomb structure hyperconcentrated floc, and a clear interface between the upper layer of water arise, When the concentration is big enough to change the rheological properties of suspended matter will become fluid mud; (2)After the surface of the seabed mud flows occur in the horizontal direction to soften together to form fluid mud; (3)A certain slope beach, channel slope, or on the surface of the valley slope sediment, under the action of wind and waves after starting form high containing water, under the action of gravity to slope toe migration formed the fluid mud;(4)When the density current energy sufficient to overcome the pressure drop along or not immediately discharged reservoir,stagnant muddy water body, which is forming dense fluid mud after settlement.

The formation of fluid mud with the following conditions: (1) Qian ning and wan zhaohui consider, Suspended sediment deposition rate is greater than the drop deposition rate; (2) Xu jianyi consider, first more fine sediment, second hydrodynamic conditions are relatively weak, third is appropriate salinity;(3)Nanjing hydraulic research institute and shanghai waterway bureau consider,First high concentrations of fine sediment, second is trend of runoff and the amount to be blended into a weak or slow the development of a mixed salt wedge, Third is weak force; (4) Li kunpeng consider ${ }^{[7]}$, First density current to carry large amounts of fine 
sediment to the dam, Second is reservoir water and sediment dynamic conditions weakened, Third is density current form can not immediately discharged library muddy water reservoir.

\section{Definition And Defining Of Fluid Mud}

Definition of fluid mud, mainly sandy density or concentration as discriminating parameters, combined with rheological properties to define, that is by the newtonian fluid rheological model bingham fluid into the lower float when mud,when fluid mud fluidity apparently disappeared,along with fluid mud density rheological parameters increases significantly when floating mud cap increase. For example, Hong roujia think that the new port fluid mud density lower limit is $1.06 \mathrm{t} / \mathrm{m}^{3}$, the upper limit is 1.20 to $1.25 \mathrm{t} / \mathrm{m}^{3}$, Chen xueliang think that lianyun port fluid mud density lower limit is $1.03 \mathrm{t} / \mathrm{m}^{3}$, The upper limit is $1.25 \mathrm{t} / \mathrm{m}^{3}, \mathrm{Li} \mathrm{jiufa}$ think that the yangtze river estuary fluid mud density lower limit is $1.04 \mathrm{t} / \mathrm{m}^{3}$, the upper limit is $1.25 \mathrm{t} / \mathrm{m}^{3}$, Wang ruicheng consider that the huanghua port fluid mud lower limit is $1.03 \mathrm{t} / \mathrm{m}^{3}$, the upper limit is $1.20 \mathrm{t} / \mathrm{m}^{3}, \mathrm{Li}$ kunpeng think xiaolangdi reservoir fluid mud desity lower limit is $1.04 \mathrm{t} / \mathrm{m}^{3}$, the upper limit is $1.23 \mathrm{t} / \mathrm{m}^{3}$; Odd and Rodger ${ }^{[8]}$ of Britain think that the lower limit of float mud $1.08 \mathrm{t} / \mathrm{m}^{3}$, the upper limit is $1.20 \mathrm{t} / \mathrm{m}^{3}$,Han winter werp $(1999)^{[9]}$ consider the definition of fluid mud containing sediment concentration above the gel point, namely 10 to $100 \mathrm{~kg} / \mathrm{m}^{3} \mathrm{more}$ cohesive sediment suspension.

Fluid mud sediment and suspended load and bed load sediment of the difference between the particle size of all sizes. In general, floating sludge particle size is less than $0.001 \mathrm{~mm}$, and its flow pattern will change along with the change of sediment concentration and sediment concentration is very small for Newtonian fluid, sediment concentration slightly enlarged to pseudo plastic fluid, sediment concentration for the bingham plastic fluid increase again.

\section{Motion Characteristic OF Fluid Mud}

Water action under fluid mud movement. Under the action of water flow, when the bingham shear stress water stress is greater than the fluid mud bottom, floating sludge surface fluctuations, as when the flow rate increased to a critical velocity, soil surface wave instability, produce the "smoke" of thread suspension sand into the water, then the flow rate is raised suspension movement velocity. Commonly used statistical methods of experimental data analysis and dimensional analysis to determine the fluid mud moving velocity raised suspension, but are generally obtained empirical formula. For the trend in the movement for a fluid mud, the situation is more complicated. Some scholars think that under tidal action, small bulk density (typically less than $1.20 \mathrm{t} / \mathrm{m}^{3}$ ) of fluid mud has great mobility, can be viewed as a plastic fluid; greater bulk density (1.20 to $1.25 \mathrm{t} / \mathrm{m}^{3}$ ) of its high viscosity fluid mud, no longer under the current role of fluctuations phenomenon, start into the water, with the water flow rate of the size or do squirm, With flow velocity the size of or do peristalsis, move or start sports. shift or start Sports. Li haolin studies have yielded floating sludge disturbing trend of thread hanging Jan critical velocity shift and formula, and when the flow rate exceeds the critical current velocity after hanging yang, sediment from erosion of velocity is proportional to the amount of the bed with water, with the bulk density inversely; and vice versa. For smaller fluid mud density, high concentrations of underflow its main form of transport.

Density Current Action Under Fluid Mud Movement.Ma huaibao, Zhang junhua, Li kunpeng and Li tao studies suggest that ${ }^{[10]}$ : (1) xiaolangdi reservoir fluid mud sediment particle size of $0.006 \mathrm{~mm}$, sediment concentration of $350 \mathrm{~kg} / \mathrm{m}^{3}$, thickness of about $0.7 \mathrm{~m}$ in 3 to 5 months;(2) Sediment particle size fine fluid mud, settling is extremely slow, with the combination of power and flood storage reservoir operation, fluid mud can discharge reservoir. For example,in 2003 the test was that water and sediment regulation based on spatial scale, which was the use of xiaolangdi reservoir subsequent density current and muddy water reservoir dam area, by opening and closing different elevations drain holes, basically forming a second pre-flooding of the yellow river the density current entrained to most of the sediment dam excretion out of the library; In August 2004 the xiaolangdi reservoir in the early fluid mud density current push by subsequent flushing together out of 
the reservoir, then the sediment concentration was up to $346 \mathrm{~kg} / \mathrm{m}^{3}$; (3)through multiple sets of secondary density current superimposed sink test, whether there is blended and defined as invasive type and interface type, as the follow-up between density flow and pre-floating sludge layer, gives the number sentenced to between two and characteristics of fluid mud layer thickness.Han qiwei analyzed the sediment sorting laws xiaolangdi reservoir, given the density smooth flow flushing, flushing and flushing effect of muddy water reservoir combination of both. Rocio and jorg (2008) conducted a similar reservoir flood two bottom density flow test interaction that when the late muddy density current proportion equal to the proportion of muddy water reservoir, density flow of muddy water has a preliminary role.

Gravity Action Under Fluid Mud Movement.Jia dongdong and shao xuejun studies show that ${ }^{[1]}$ :(1) Three gorges reservoir on the use of a significant increase of sedimentation reservoir area,the larger the total dam siltation causes of both the three-dimensional characteristics of the dam flow regime related, but also with reservoir storage early water particles characteristic related to sludge dam;(2)Initial impoundment deposited near the dam of the finer sediment particles (particle size of 0.004 to $0.008 \mathrm{~mm}$ ), the initial dry density is low,so that the sludge showed some fluid mud characteristics; (3) Large amount of siltation dam is mainly caused by the flow characteristics of the river gully, while larger sludge thickness deep trench at the base,mainly due to appear before the level of siltation is gravity-like floating sludge in sludge;(4)Use of sediment deposition process when the full three-dimensional numerical model to simulate suspended sediment near the dam of the sludge characteristics without considering floating sludge dam; in the river movement and brought together along the thalweg in a deep trench in the substrate sediment deposition along in good agreement with the measured value, but there is a big difference with the measured cross-section profile, after considering fluid mud sludge characteristics (under its own gravity to the bottom of the deep trench movement) dam sludges the calculated distribution of sludge along the section, longitudinal section of the change process and measured results are in line with the dam thalweg better.

Waves Action Under Fluid Mud Movement.Wave and sand interaction is very complex, wave both cause fluctuations in fluid mud, suspension, transport, floating mud can turn affect wave propagation and attenuation.Zhao zidan studies suggest that: for small density of fluid mud in the fall the soil surface wave action produces a corresponding fluctuation and surface waves, and the volatility of the soil surface with floating strengthen and increase the surface waves, but when the water wave after the wave height exceeds a certain limit.Cao zude studies suggest that: the role of the waves, when the fluid mud density is small, floating sludge interface with the oscillating surface wave of ups and downs accordingly, broken only when the wave appears when the boundary wave The cause of floating sludge suspended sediment will occur locally broken; when the fluid mud density greater wave action occurs, floating loose mud, grading in the occurrence of fine particles suspended sediment. Zhao jinsheng and liu jiaju studies suggest that: in the common fluid mud density wave and the general situation, floating sludge interface wave velocity surface wave velocity of 0.56 to 0.86 .Zhao zidan gives the maximum depth of expression under the influence of wave action, the boundary wave amplitude gradually transferred to the internal fluid mud, and indicate the role of waves can not only cause a boundary wave, and can carry a floating sludge along the bottom of the wave forward direction transport, and gives the case a flow rate of fluid mud distributed inside.

Wind Wave And Tidal Currents Action Under Fluid Mud Movement.Sea motion characteristics of fluid mud is movement in the joint action of wind, waves and tide of. It is different from bedload or suspended sediment in the sea breeze, the movement under waves and tidal action, but also from fluid mud in the general case of motion, so the unique movement.On the coast or estuaries open, driven by wind, waves and tide combined effect of fluid mud of transport and the wind velocity, the fluid mud advancing tide wave velocity and flow rates. The direction in which these three rate is fluid mud and sediment transport in the direction. Luo zhaosen based on the study liu jiaju and and li haolin analysis results the expression of wind, wave, tidal currents fluid mud sediment transport capacity and sediment transport rates. 


\section{Conclusion}

Motion characteristics of fluid mud is subject to many factors, coupled with restrictions observations and experimental conditions, most of the existing empirical research has not yet reached the point where accurate description, but also a lack of research has universality. Therefore, the study on the impact of the mechanism of fluid mud channel, reservoirs, port engineering needs further strengthening and improvement.

\section{Acknowledgements}

The research was supported by the national natural Science foundation of china(NSFC) (NO.51179072,51309110,51509103), the mwr special public service sectors(201401023), the central-level nonprofit research institute fund(HKY-JBYW-2014-12), the fund open topic of the yellow river key laboratory of the ministry of water resources (2013007).

\section{Reference}

[1]Inglis ,C. C. and Allen ,H. H., The regimen of the Thames Estuary as affected by currents ,salinities and river flows[C]. Proceedings of the Institution of Civil Engineers,Maritime Waterways Engineering Division Meeting,1957,Vol7,p827-879.

[2]Migniot ,C., A study on the physical properties of various forms of very fine sediments and their behaviour under hydrodynamic action[C].La Houille Blanche,1968,Vol 7,p591-620.

[3]NEDECO, Surinam transportation study[R], Netherlands Engineering Consultants, 1968.

[4]Kirby ,R. and Parker ,W. R.,Distribution and behavior of fine sediment in the Severn estuary and inner Bristol Channel[J].UK,Canadian Journal of Fisheries and Aquatic Science,1983, Vol 40,p83-95.

[5]Parker,W.R. and Hooper ,P.M., Criteria and methods to determine navigable depth in hyper-concentrated sediment layers,in:Proceedings of Hydro Port 94[C].International Conference on Hydro Technical Engineering for Port and Harbour Construction,October,Yokosuka,Japan,1994,

p1211-1224.

[6]Zhao jinsheng,zhao zidan,cao zude. A preliminary study newport movement of fluid mud under wave action[J].Newport back silt research,1963(1),p40-59.

[7]Li kunpeng,wang rui,ma huaibao.Hydrodynamic characteristics of the fluid mud layer Xiaolangdi reservoir[J].China rural water and hydropower,2013(1),p35-38.

[8]Odd N V M ,Rodger J G.An analysis of the behaviour of fluid mud in estuarine[R].J.HR Report SR 84,1986,p108-117.

[9]Han Winter werp,C.,On the dynamics of high concentrated mud suspensions[J],No 99-3 of Delft University of Technology,Faculty Civil Engineering and Geosciences,ISSN 0169-6548,1999,p1-160.

[10]Ma huaibao, zhang junhua,li tao,li kunpeng. Xiaolangdi reservoir sediment key technologies of efficient[R]. Yellow river Institute of hydraulic research,2011,p41-89.

[11]Jia Dongdong, Shao Xuejun, Zhang Xingnong, et al. Sedimentation Patterns of Fine-Grained Particles in the Dam Area of the Three Gorges Project: 3D Numerical Simulation. Journal of Hydraulic Engineering (ASCE), 2013.139(6): 669-674. 